\title{
DEA-Based Re-allocation Model with Constant the Efficiency and Improvement of Undesirable Factors. The Case Study in Tejarat Bank of Iran
}

\author{
S. Madadi ${ }^{1}$, F. Hosseinzadeh Lotfi ${ }^{*},{ }^{2}$, M. Rostamy-Malkhalifeh ${ }^{3}$, M. Fallah \\ jelodar $^{4}$
}

\begin{abstract}
Resource allocation is a problem that commonly appears in organization with a centralized decision making (CDM), who controls the units. The aim of central decision making is to allocate resources in such a way that the organization get the most benefit. Some Data Envelopment Analysis (DEA) researchers presented DEA-based resource allocation models by paying attention to energy saving and environmental pollution reduction. In this paper, we expanded a resource allocation model for 25 branches of an Iranian Tejarat bank, so that determined how much decision making (DM) can save on energy and manpower hours, so that undesirable outputs like non-performing loans are significantly reduced in a way that achieve the minimum reduction of desirable outputs while unchanged the performance of each unit after re-allocation. The result of the implementation of the model shows that in total with a $10 \%$ and $23 \%$ reduction in staff and costs respectively can result in the $0.09 \%$ reduction of deposits and $56 \%$ of non-performing loans.
\end{abstract}

Keywords: resource allocation, data envelopment analysis, energy saving.

Manuscript was received on 29/03/2017, revised on 06/09/2017 and accepted for publication on 03/02/2018

\section{Introduction}

Initially, Data Envelopment Analysis (DEA) was used to measure technical efficiency, but is now widely used in resource allocation and production design. Since Charnes et al. [10] developed Data Envelopment Analysis (DEA), it has become a popular method for efficiency analysis. Resource allocation problem is currently under active research in the DEA literature. Resource allocation is a problem that commonly appears in organization with a centralized decision making $(\mathrm{CDM})$ environment in which a set of units are operating under a central decision maker With

\footnotetext{
* Corresponding author

${ }^{1}$ Department of Mathematics, Science and Research Branch, Islamic Azad University, Tehran, Iran, Email: sima.madadi@gmail.com

${ }^{2}$ Department of Mathematics, Science and Research Branch, Islamic Azad University, Tehran, Iran, Email: farhad@hosseinzadeh.ir
}

${ }^{3}$ Department of Mathematics, Science and Research Branch, Islamic Azad University, Tehran, Iran, Email: Mohsen_rostamy@yahoo.com

4 Department of Mathematics, Ayatollah Amoli Branch, Islamic Azad University, Amol, Iran, Email: Mehdi.fallah_jelodar@yahoo.com 
power to control some decision parameters like resources of those units $[4,34]$. The aim of central decision making is to allocate resources in such a way that the most beneficial results by allocating these resources to its organization[15,16]. The problem of resource allocation has become one of the classical applications of management science and has great practical application value (see: [6], [16], [19]) [27],[13], [12]). Lozano and Villa [28] presented two centralized resource allocation models; one type, considers reduction of the total consumption of every input by all units, the other type related to separate reductions for each input. For other extensions of Lozano and Villa's model [28], refer to [22], [29]. Asmild et al. [5] considered one of the models of Lozano and Villa [29] and modified it to adjust the inefficient units. Korhonen and Syrjanen [27] developed an approach based on DEA and multiple objective linear programing (MOLP) and applied it to a resource allocation problem. They assumed that the units are able to modify their production plan with in the production possibility set only according to certain values, when Decision Maker (DM) was interested in maximizing the total amount of outputs produced by allocating the additional resources to units. They defined a transformation possibility set for each Decision Making Unit (DMU) with two assumption. The first one is to assume that the unit's efficiency stays constant during the planning period and the other assumption is that each unit can have a proportion scaling of the existing production changes in inputs and outputs. Li et al. [19] combined energy consumption reduction by using resource allocation with considering undesirable outputs and proposed the multiple objective model for resource allocation under the energy saving constraints. Since saving energy effect on the desirable and undesirable outputs, the model has been designed in a way that reduction proportion of desirable output is less than reduction proportion of undesirable output. Amirteimoori and Kordrostami [3] extended a method that implemented the demand and supply changes in a centralized decision making. Fang [13] presented a generalized DEA model for centralized resource allocation with the assumption of adjustable and non-adjustable inputs, then he analyzed the structural efficiency using structural efficiency presented by Li and cheng [33]. Hatami-marbini et al. [17] proposed an alternative DEA model based on the Goal programing (GP) concept to the total weight flexibility in the conventional DEA models centrally imposed resource or output reduction across the reference set. They show how much the inputs and outputs of each DMU should be reduced to increase the efficiency score of all the DMUs and they compared their model with Amirteimoori and Emrouznejad [2] method. Hosseinzadeh Lotfi et al. [23] increase or decrease non-radially all of the inputs and outputs at the same time by solving a centralized resource allocation for enhanced Russell model. Hosseinzadeh Lotfi et al. [22] presented the stochastic centralized resource allocation in order to allocate centralized resources where inputs and outputs are stochastic. Ehsan Momeni et al. [31] presented model considers all decision making units (DMUs) together and improve whole efficiency of them by reducing total emission permit as undesirable outputs. Wu et al. [35] introduced a DEA-based approach to allocate China's national $\mathrm{Co}_{2}$ emissions and energy intensityreduction. Zhu et al. [38] studied classification of natural resources of china and used an input-oriented model based on slack for measuring the efficiency of provinces, then they provided an approach based on DEA for allocating the total natural resources. Many findings of DEA have been used for measuring environmental performance. (see: $[32,18,11$, 25, 30, 37] ). Akbari et al. [1] designed a mixed structure to measure the efficiency of branches of Tejarat Banks in Iran according to their policies.In some studies, DEA and multiple objective linear programing (MOLP) integrated to deal resource allocation problem [35]. Goal programing (GP) as a method for solving multiple objective tries to achieve several goals simultaneously, while deviation from goal is also allowed. The aim of GP is giving a special target value to each objective function so that minimizes the unwanted deviations from intended goals (see: $[7,8,21,20,9,24$, $36,16])$. In this paper, the efficiency score of 25 branches of an Iranian Tejerat bank in the present of undesirable outputs are calculated, Then we paid to see how much energy and manpower hours can be saved so that undesirable outputs such as non-performing loans are significantly reduced, 
also the desirable outputs will be less affected and unchanged the performance of branches after reallocation. For this purpose, the innovation of this paper are:

- Exhibit a new model for resource allocation with the undesirable outputs when saving energy leads to reduce desirable and undesirable output, the proportion of undesirable outputs reduction is bigger than desirable output reduction proportion when the efficiency of each unit remain unchanged after re-allocation.

- When Decision maker (DM) has a specific condition on the reduction variables, then the model is modified by Goal programing (GP) in a way that it becomes feasible.

The paper is organized as follows: Section 2 provides a preliminaries review on the DEA-based resource allocation issues. In section 3, we proposed a DEA-based interactive approach to resource allocation based on unchanged efficiency, so that we can have energy saving and reduction of undesirable outputs. In section 4 we show a numerical example to illustrate the application of the proposed model for 25 branches of Iranian Tejarat bank. Finally conclusions are shown in section 5.

\section{Preliminaries}

Consider an organization consisting of $n$ homogeneous DMU. $\operatorname{DMU}_{\mathrm{j}}(\mathrm{j}=1, \ldots, \mathrm{n})$ uses $\mathrm{m}$ inputs; $\quad X_{j}=\left(x_{1 j}, \ldots, x_{m j}\right)^{T}$ To produce s desirable outputs; $Y_{j}^{g}=\left(y_{1 j}^{g}, y_{2 j}^{g} \ldots, y_{s j}^{g}\right)^{T}$ and $\mathrm{p}$ undesirable outputs; $\quad Y_{j}^{b}=\left(y_{1 j}^{b}, y_{2 j}^{b} \ldots, y_{p j}^{b}\right)^{T}$ and assume that $X>0, \quad Y^{g}>0, \quad Y^{b}>0$.

Efficiency measurement in DEA is usually based on the assumption that inputs have to be minimized. In situations that undesirable outputs may be presented in the production process, in order to improve the performance of a DMU the undesirable outputs and inputs should be decreased.

The production possibility set $\mathrm{T}$ according to [10] is defined by:

$$
T=\left\{\left(x, y^{g}, y^{b}\right) \mid x \geq \sum_{j=1}^{n} \lambda_{j} x_{j}, y^{g} \leq \sum_{j=1}^{n} \lambda_{j} y_{j}^{g}, y^{b} \geq \sum_{j=1}^{n} \lambda_{j} y_{j}^{b}, \lambda_{j} \geq 0, j=1, \ldots, n\right\}
$$

Seiford and Zhu [32] pointed that standard DEA models can be used to improve performance via decreasing the undesirable outputs and increasing the desirable outputs. They considered the same coefficients to increase desirable outputs and decrease undesirable outputs in order to evaluate $\mathrm{DMU}_{\mathrm{o}}$. But we preferred different coefficients to increase desirable outputs and decrease undesirable outputs. So we consider the output-oriented model to evaluate the performance of $\mathrm{DMU}_{\mathrm{o}}$ with CRS assumption as follows: 


$$
\begin{array}{ll}
\max & \varphi_{o}-\varphi_{o}^{\prime} \\
\text { s.t. } \quad & \sum_{j=1}^{n} \lambda_{j} x_{j} \leq x_{o} \\
& \sum_{j=1}^{n} \lambda_{j} y_{j}^{g} \geq \varphi_{o} y_{o}^{g} \\
& \sum_{j=1}^{n} \lambda_{j} y_{j}^{b} \leq \varphi_{o}^{\prime} y_{o}^{b} \\
& \varphi_{o} \geq 1 \\
& \varphi_{o}^{\prime} \leq 1 \\
& \lambda_{j} \geq 0 \quad j=1, \ldots, n
\end{array}
$$

Definition: $\mathrm{DMU}_{\mathrm{o}}$ is efficient if and only if $\varphi_{o}^{*}=\varphi_{o}^{* \prime}=1$ otherwise, $\mathrm{DMU}_{\mathrm{o}}$ is inefficient.

Note that, the primary objective function was as $\begin{aligned} & \max \varphi_{o} \\ & \min \varphi_{o}^{\prime}\end{aligned}$, which was written to linearize using the above sum of the weighed method.

\section{Re-allocation based on unchanged efficiency}

Supposing that there is a decision making environment in the organization with power to control the resources of the DMUs. Korhonen and Syrjanen [27] assumed that DM is interesting in maximizing the amount of outputs by allocating available additional resources to units. Li et al. [19] discuss about saving energy and reducing pollution by resource allocation in the next period. The purpose of their model is to re-evaluation of the inputs in a way that achieve the minimum reduction of desirable outputs and maximum reduction of undesirable outputs also the relevant DMUs consume less inputs to produce. In this paper, we proposed a model for the allocation of resources among a set of DMUs. Each unit consumes multiple inputs resources to produce multiple outputs, in which some are desirable and others are undesirable outputs, with aiming to save energy and reduce undesirable outputs so that decision maker (DM) has decided the efficiency of each DMU to stay unchanged. Initially, we determine the optimal value $\varphi_{o}^{*}, \varphi_{o}^{*}$ for each $\mathrm{DMU}_{\mathrm{j}}(\mathrm{j}=1, \ldots, \mathrm{n})$ using model (2). Then, when $\mathrm{T}$ is based on CRS assumption, we can reformulate the allocation resource model based on saving energy and reduction environmental pollution so that efficiency of each DMU unchanged, that is:

$$
\left(\begin{array}{c}
\left(x_{j}-\Delta x_{j}\right) \\
\varphi_{j}^{*}\left(y_{j}^{g}-\Delta y_{j}^{g}\right) \\
\varphi_{j}^{* *}\left(y_{j}^{b}-\Delta y_{j}^{b}\right)
\end{array}\right) \in T \quad \mathrm{j}=1, \ldots, \mathrm{n}
$$

And we have the following MOLP model: 
$\min \Delta Y^{g}=\sum_{j=1}^{n} \sum_{r=1}^{s} \frac{\Delta y_{r j}^{g}}{y_{r j}}$
$\max \quad \Delta X=\sum_{j=1}^{n} \sum_{i=1}^{m} \frac{\Delta x_{i j}}{x_{i j}}$

s.t.

$$
\begin{aligned}
& x_{i j}-\Delta x_{i j} \geq \sum_{l=1}^{n} \lambda_{j l} x_{i l} \quad j=1, \ldots, n, i=1, \ldots, m \\
& \varphi_{j}^{*}\left(y_{r j}^{g}-\Delta y_{r j}^{g}\right) \leq \sum_{l=1}^{n} \lambda_{j l} y_{r l}^{g} \quad j=1, \ldots, n, r=1, \ldots, s \\
& \varphi_{j}^{* *}\left(y_{p j}^{b}-\Delta y_{p j}^{b}\right) \geq \sum_{l=1}^{n} \lambda_{j l} y_{p l}^{b} \quad j=1, \ldots, n, p=1, \ldots, P \\
& 0 \leq \Delta y_{p j}^{b} \leq y_{p j}^{b} \quad j=1, \ldots, n, p=1, \ldots, P \\
& 0 \leq \Delta y_{r j}^{g} \leq y_{r j}^{g} \quad j=1, \ldots, n, r=1, \ldots, s \\
& 0 \leq \Delta x_{i j} \leq x_{i j} \quad j=1, \ldots, n, i=1, \ldots, m \\
& \lambda_{j l} \geq 0 \quad j=1, \ldots, n, l=1, \ldots, p
\end{aligned}
$$

$\Delta x_{j}$, represents the saving amount of inputs, and $\Delta y_{j}^{g}, \Delta y_{j}^{b}$ represent the reduction amounts of desirable and undesirable outputs respectively in $\mathrm{DMU}_{\mathrm{j}} \cdot \varphi_{o}^{*}, \varphi_{o}^{*}$; are optimal values obtained from model (2).

Model (3) is maximizing the total proportion of inputs changes and minimizing the total proportion of desirable outputs changes. While it assumes that the units are unable to change their efficiency score during the planning period.

Model (3) is a multiple objective programing. We can transform the multiple objective function model (3) in to the following single objective function:

$\min \Delta y^{g}-\Delta x=\sum_{j=1}^{n} \sum_{r=1}^{s} \frac{\Delta y_{r j}^{g}}{y_{r j}}-\sum_{j=1}^{n} \sum_{i=1}^{m} \frac{\Delta x_{i j}}{x_{i j}}$

Now, we assuming that the manager conditions $\sum_{j=1}^{n} \Delta y_{j}^{b} \geq F, \Delta y_{j}^{g} \leq D_{j}, \quad \Delta x_{j} \leq C_{j}$ impose the problem also. $F \in R_{\geq 0}^{P}, C_{j} \in R_{\geq 0}^{s}, D_{j} \in R_{\geq 0}^{m}$ are conditions imposed by the manager. By adding this constraint to the problem (3), it may be infeasible because of the management's expectation is unattainable. Therefore the model is modified by Goal programing (GP) in a way that it becomes feasible. 
$\min \quad Z_{1}=N+\sum_{j=1}^{n} V_{j}+\sum_{j=1}^{n} W_{j}$

$\max \sum_{j=1}^{n} \sum_{r=1}^{s} \frac{\Delta y_{r j}^{g}}{y_{r j}^{g}}-\sum_{j=1}^{n} \sum_{i=1}^{m} \frac{\Delta x_{i j}}{x_{i j}}$

s.t.

$$
\begin{aligned}
& x_{i j}-\Delta x_{i j} \geq \sum_{l=1}^{n} \lambda_{j l} x_{i l} \quad j=1, \ldots, n, i=1, \ldots, m \\
& \varphi_{j}^{*}\left(y_{r j}^{g}-\Delta y_{r j}^{g}\right) \leq \sum_{l=1}^{n} \lambda_{j l} y_{r l}^{g} \\
& \varphi_{j}^{* *}\left(y_{p j}^{b}-\Delta y_{p j}^{b}\right) \geq \sum_{l=1}^{n} \lambda_{j l} y_{p l}^{b} \\
& 0 \leq \Delta x_{j} \leq C_{j}-V_{j} \\
& 0 \leq \Delta y_{j}^{g} \leq D_{j}-W_{j} \\
& \sum_{j=1}^{n} \Delta y_{j}^{b} \geq F-N \\
& \lambda_{j l} \geq 0 \quad j=1, \ldots, n, r=1, \ldots, s
\end{aligned}
$$

In constraints (5-4), if the management's expectation for reaching $C_{j}$ are unattainable, deviation variables $V_{j}$ modified it, and it makes the problem possible. Also constraint (5-5), (5-6). Suppose $\left(\lambda_{j}^{*}, \Delta x_{j}^{*}, \Delta y_{j}^{g^{*}}, \Delta y_{j}^{b^{*}}, j=1, \ldots, n\right)$ are the optimal solution for above model.

Theorem 1. Model (5) is feasible.

Proof: Because we have $\left(\begin{array}{c}\left(x_{j}-\Delta x_{j}\right) \\ \varphi_{j}^{*}\left(y_{j}^{g}-\Delta y_{j}^{g}\right) \\ \varphi_{j}^{* *}\left(y_{j}^{b}-\Delta y_{j}^{b}\right)\end{array}\right) \in T$ in model (2) then by choosing $\Delta x_{j}=\Delta y_{j}^{g}=\Delta y_{j}^{b}=0$, constraints (5-1) - (5-3) are established. Also deviation variables N, W, V in constraints (5-4)-(5-6) make these constraints possible.

Theorem 2. Efficiency of units remain unchanged after re-allocation.

Proof: Consider the re-allocation optimal values $x_{j}-\Delta x_{j}^{*}, y_{j}^{g}-\Delta y_{j}^{g^{*}}, y_{j}^{b}-\Delta y_{j}^{b^{*}}$ obtained with the model (5). By re-evaluate these new values by the model (2), we show that $\eta_{o}^{*}=\varphi_{o}^{*}, \eta_{o}^{* *}=\varphi_{o}^{* *}$. 
For this purpose, suppose $\eta_{o}^{*}, \eta_{o}^{*}, \mu_{j}^{*}, j=1, \ldots, n$ are the optimal solution to evaluate $\mathrm{DMU}_{\mathrm{o}}$ after reallocation for the following model:

$$
\begin{array}{ll}
\max & \eta_{o}-\eta_{o}^{\prime} \\
\text { s.t. } & \sum_{j=1}^{n} \mu_{j} x_{j} \leq x_{o}-\Delta x_{o}^{*} \\
& \sum_{j=1}^{n} \mu_{j} y_{j}^{g} \geq \eta_{o}\left(y_{o}^{g}-\Delta y_{o}^{g^{*}}\right) \\
& \sum_{j=1}^{n} \mu_{j} y_{j}^{b} \leq \eta_{o}^{\prime}\left(y_{o}^{b}-\Delta y_{o}^{b^{*}}\right) \\
& \eta_{o} \geq 1 \\
& \eta_{o}^{\prime} \leq 1 \\
& \mu_{j} \geq 0 \quad j=1, \ldots, n
\end{array}
$$

If assumed $\eta_{o}^{*} \neq \varphi_{o}^{*}, \eta_{o}^{* *} \neq \varphi_{o}^{\prime *}$, so there are four cases. Suppose $\eta_{o}^{*}<\varphi_{o}^{*}$ and $\eta_{o}^{* *}>\varphi_{o}^{* *}$ then we have $\eta_{o}^{*}\left(y_{o}^{g}-\Delta y_{o}^{g^{*}}\right)<\varphi_{o}^{*}\left(y_{o}^{g}-\Delta y_{o}^{g^{*}}\right) \leq \sum_{l=1}^{n} \lambda_{l}^{*} y_{l}^{g} \quad$ from $\quad$ the $\quad$ constraint $\quad$ (5-2) and $\sum_{l=1}^{n} \lambda_{l}^{*} y_{l}^{b} \leq \varphi_{o}^{*}\left(y_{o}^{b}-\Delta y_{o}^{b^{*}}\right)<\eta_{o}^{*}\left(y_{o}^{b}-\Delta y_{o}^{b^{*}}\right)$ from the constraint (5-3). By placing $\mu_{j}=\lambda_{j}^{*}(j=1, \ldots, n)$ in model (6), we will have a solution that it is contradict the optimality of $\eta_{o}^{*}$ according to the definition of the model (6) objective function. Now we suppose $\varphi_{o}^{*}<\eta_{o}^{*}$ and $\varphi_{o}^{*}<\eta_{o}^{* *}$ then we have $\varphi_{o}^{*}\left(y_{o}^{g}-\Delta y_{o}^{g^{*}}\right)<\eta_{o}^{*}\left(y_{o}^{g}-\Delta y_{o}^{g^{*}}\right) \leq \sum_{j=1}^{n} \mu_{j}^{*} y_{j}^{g}$ from (6-2) and $\sum_{l=1}^{n} \lambda_{l}^{*} y_{l}^{b} \leq \varphi_{o}^{* *}\left(y_{o}^{b}-\Delta y_{o}^{b^{*}}\right)<\eta_{o}^{* *}\left(y_{o}^{b}-\Delta y_{o}^{b^{*}}\right)$ from (5$3)$. Which shows we will have a solution for model (6), which contradict the optimality of $\eta_{o}^{*}$ in model (6). Likewise, other cases will be contradicted. Therefore, $\eta_{o}^{*}=\varphi_{o}^{*}, \eta_{o}^{*}=\varphi_{o}^{* *}$

\section{Numerical examples}

In the current section, we consider 25 branches of the Iranian Tejarat bank that is derived from Kordrostami et al. [26] study, as the number of staff and costs are considered as input indicators. The costs contain staff costs and operational costs of bank branches. Furthermore, deposits, income, and granted loan are taken as desirable outputs, while non-performing loans are deemed as undesirable outputs. The deposit in each branch is the result of the attraction of the funds from customers. Income includes interest income and non-interest income. Granted loans are loans granted by governmental sectors. Non-performing loans are loans that are in default, according to the bank regulations [26]. Suppose that central manager of the Tejarat bank is willing to save costs and reduce bank staff, make changes in inputs and outputs whereas the performance of each branch remains constant. Since saving on inputs affects outputs, the manager wants the changes to be such that the percentage of undesirable output reductions is greater than the percentage of desirable output reductions and will have saving on costs and part-time staff by maintaining the efficiency of each branch. Inputs, outputs Data and optimal values obtained from model (2) are display in Table 1: 
Table 1. Input and Output data for 25 bank branches

\begin{tabular}{|c|c|c|c|c|c|c|c|c|}
\hline \multirow[b]{2}{*}{ Branches } & \multicolumn{2}{|c|}{ Input } & \multicolumn{3}{|c|}{ Desirable outputs } & \multicolumn{3}{|l|}{ Undesirable output } \\
\hline & Staff & costs & Deposits & Income & Granted Loans & Non-performing Loans & $\varphi^{*}$ & $\varphi^{*}$ \\
\hline 1 & 9 & 8404 & 205070 & 11990 & 151088 & 5988 & 1 & 1 \\
\hline 2 & 8 & 7469 & 235492 & 6284 & 147547 & 7512 & 1 & 1 \\
\hline 3 & 8 & 7473 & 237013 & 12158 & 163024 & 46960 & 1 & 1 \\
\hline 4 & 11 & 10333 & 209724 & 2788 & 105005 & 18705 & 1.14 & 0.19 \\
\hline 5 & 13 & 12145 & 38541 & 16667 & 98959 & 8476 & 1 & 0.7 \\
\hline 6 & 8 & 7495 & 138238 & 6780 & 108155 & 2734 & 1 & 1 \\
\hline 7 & 7 & 6507 & 183835 & 3404 & 82560 & 12614 & 1.28 & 0.28 \\
\hline 8 & 10 & 9325 & 287007 & 9988 & 94015 & 24087 & 1 & 1 \\
\hline 9 & 6 & 5601 & 181129 & 1028 & 105531 & 3421 & 1 & 1 \\
\hline 10 & 10 & 9410 & 240364 & 24473 & 196128 & 43298 & 1 & 1 \\
\hline 11 & 5 & 4674 & 126794 & 6195 & 38357 & 3877 & 1 & 1 \\
\hline 12 & 8 & 7477 & 207637 & 2602 & 96637 & 4807 & 1.09 & 0.66 \\
\hline 13 & 7 & 6554 & 239988 & 7152 & 88133 & 9494 & 1 & 1 \\
\hline 14 & 7 & 6586 & 154348 & 2065 & 78916 & 15323 & 1.50 & 0.23 \\
\hline 15 & 9 & 8380 & 189020 & 5515 & 69399 & 1988 & 1 & 1 \\
\hline 16 & 8 & 7469 & 122329 & 6796 & 72600 & 3965 & 1.21 & 0.62 \\
\hline 17 & 8 & 7468 & 194806 & 7442 & 59239 & 3647 & 1 & 0.78 \\
\hline 18 & 7 & 6555 & 113540 & 9933 & 70377 & 1916 & 1 & 1 \\
\hline 19 & 7 & 6568 & 193148 & 2468 & 86643 & 7820 & 1.24 & 0.46 \\
\hline 20 & 9 & 8400 & 221505 & 2527 & 107904 & 19845 & 1.08 & 0.18 \\
\hline 21 & 8 & 7455 & 266868 & 23224 & 62528 & 8106 & 1 & 1 \\
\hline 22 & 10 & 9340 & 161850 & 2420 & 78858 & 25091 & 1.48 & 0.14 \\
\hline 23 & 12 & 11170 & 208355 & 4511 & 114262 & 9010 & 1.11 & 0.46 \\
\hline 24 & 7 & 6560 & 240393 & 5163 & 118890 & 3645 & 1 & 1 \\
\hline 25 & 7 & 6569 & 174337 & 420 & 137342 & 37853 & 1 & 1 \\
\hline
\end{tabular}

At first, we evaluate the performance of $\operatorname{DMU}_{\mathrm{j}}(\mathrm{j}=1, \ldots, 25)$ with model (2) then put determined $\varphi_{j}^{*}, \varphi_{j}^{*}(\mathrm{j}=1, \ldots, \mathrm{n})$ in model $(5)$ by placing parameters as follows:

$C_{j}=0.30 x_{j}, \quad D_{j}=0.10 y_{j}^{g}, \quad F=0.60 \sum_{j=1}^{n} y_{j}^{b}$

The optimal values of this model can be obtained by lexicography's prioritization method. The first objective function is considered as the first priority for the problem to be feasible. In other words, $Z_{1}^{*}>0$ means that the deviation variable made the problem feasible, and if we did not consider the problem as GP, then it would be infeasible. The second step is the sum of two weighted next objective functions, in order to minimize desirable output reduction and maximize saving inputs on the optimal solution, which is obtained from the first step. The results using the Gams software are as follows.

Reduction value of inputs and outputs indicated in the tables 2 and 3.

The first and second columns in the table 2 represent the reduction amount of staff and costs. The third and fourth columns represent the proportion of staff and costs changes. Also table 3 is interpreted. For example in branch 10, if 20 percent of staff and 21 percent of costs are reduced, the deposits as desirable output will be reduced by 10 percent, instead, non-performing loans can be reduced by up to 92 percent through strong guarantees while unchanged the performance of unit.in unit 5 model reduces each inputs by $30 \%$ and reduces undesirable output by $69 \%$ while none of the desirable outputs need to be reduced. That is because inefficiency only exist in undesirable output in 
branch 5 (as can be seen in $\varphi_{5}^{*}=1, \varphi_{5}^{* *}=0.7$ ). Unit 3 located on the efficient hyperplane but the objective function of the problem allows it to reduce desirable output and undesirable output while unchanged the efficiency of unit.

Table 2. Reduction value of inputs

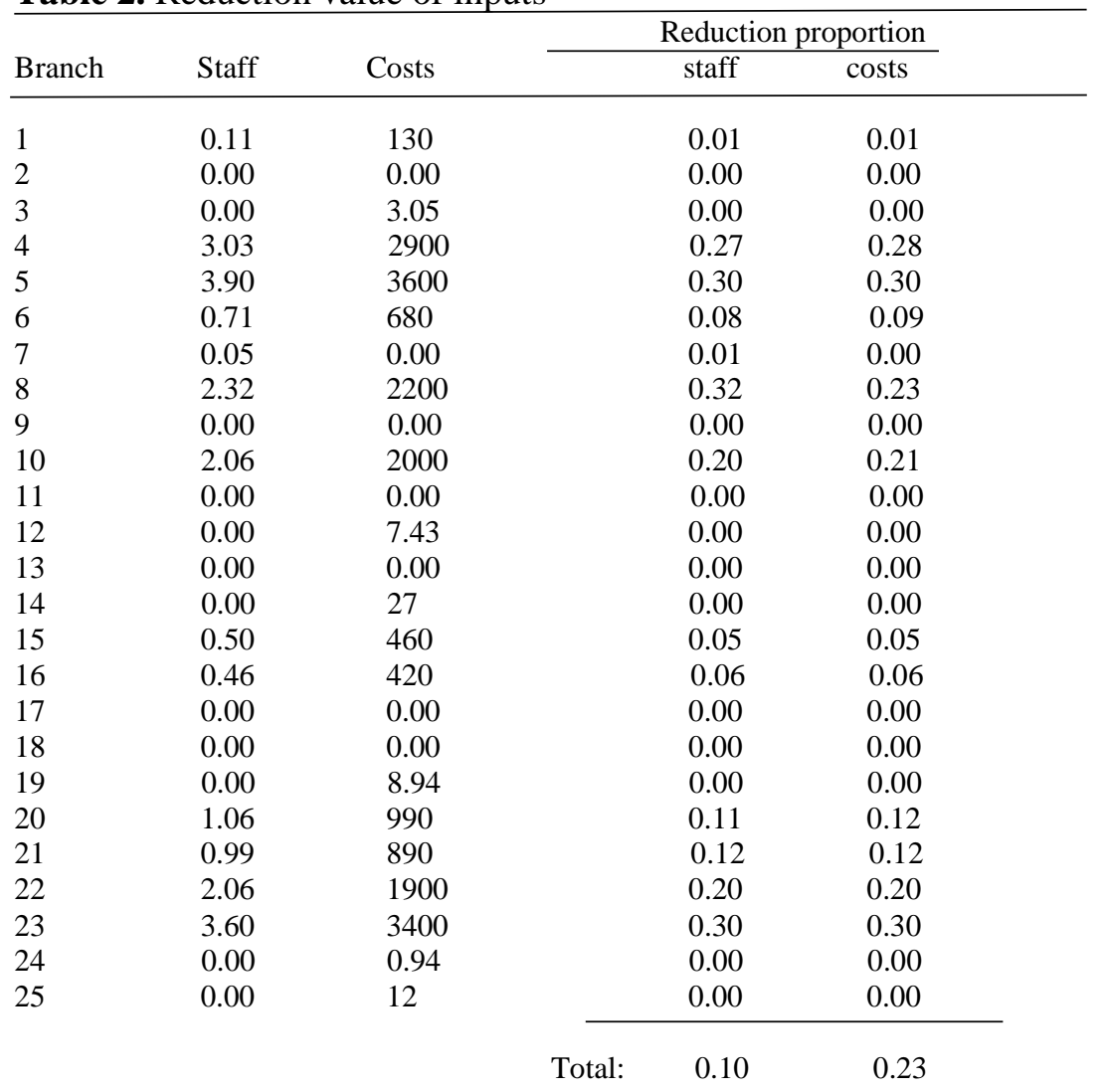

Table3: Reduction value of outputs

\begin{tabular}{|c|c|c|c|c|c|c|c|c|}
\hline \multirow{2}{*}{ Branch } & \multirow{2}{*}{ Deposits } & \multirow{2}{*}{ Income } & \multirow{2}{*}{ Granted loans } & \multirow{2}{*}{$\begin{array}{l}\text { Non-performing } \\
\text { loans }\end{array}$} & \multicolumn{3}{|c|}{ Reduction proportion } & \multirow[b]{2}{*}{$\begin{array}{c}\text { Non-performing } \\
\text { Loans }\end{array}$} \\
\hline & & & & & Deposits & Income & Granted Loans & \\
\hline 1 & 21000 & 0.00 & 0.00 & 4000 & 0.10 & 0.00 & 0.00 & 0.66 \\
\hline 2 & 24000 & 0.00 & 0.00 & 4700 & 0.10 & 0.00 & 0.00 & 0.62 \\
\hline 3 & 24000 & 0.00 & 0.00 & 44000 & 0.10 & 0.00 & 0.00 & 0.93 \\
\hline 4 & 21000 & 0.00 & 0.00 & 4400 & 0.10 & 0.00 & 0.00 & 0.23 \\
\hline 5 & 0.000 & 0.00 & 0.00 & 5900 & 0.00 & 0.00 & 0.00 & 0.69 \\
\hline 6 & 14000 & 0.00 & 0.00 & 810 & 0.10 & 0.00 & 0.00 & 0.30 \\
\hline 7 & 18000 & 0.00 & 0.00 & 1100 & 0.09 & 0.00 & 0.00 & 0.09 \\
\hline 8 & 29000 & 0.00 & 0.00 & 17000 & 0.10 & 0.00 & 0.00 & 0.70 \\
\hline 9 & 18000 & 0.00 & 0.00 & 150 & 0.10 & 0.00 & 0.00 & 0.04 \\
\hline 10 & 24000 & 0.00 & 0.00 & 40000 & 0.10 & 0.00 & 0.00 & 0.92 \\
\hline 11 & 0.000 & 0.00 & 0.00 & 0.00 & 0.00 & 0.00 & 0.00 & 0.00 \\
\hline 12 & 21000 & 0.00 & 0.00 & 790 & 0.10 & 0.00 & 0.00 & 0.16 \\
\hline 13 & 24000 & 0.00 & 0.00 & 6200 & 0.10 & 0.00 & 0.00 & 0.65 \\
\hline 14 & 15000 & 0.00 & 0.00 & 1800 & 0.09 & 0.00 & 0.00 & 0.11 \\
\hline 15 & 19000 & 0.00 & 0.00 & 18 & 0.10 & 0.00 & 0.00 & 0.01 \\
\hline 16 & 12000 & 0.00 & 0.00 & 860 & 0.10 & 0.00 & 0.00 & 0.21 \\
\hline 17 & 19000 & 0.00 & 0.00 & 740 & 0.09 & 0.00 & 0.00 & 0.20 \\
\hline 18 & 0.000 & 0.00 & 0.00 & 0.00 & 0.00 & 0.00 & 0.00 & 0.00 \\
\hline
\end{tabular}




$\begin{array}{llllllllll}19 & 19000 & 0.00 & 0.00 & 700 & 0.09 & 0.00 & 0.00 & 0.09 \\ 20 & 22000 & 0.00 & 0.00 & 4200 & 0.10 & 0.00 & 0.00 & 0.21 \\ 21 & 27000 & 0.00 & 0.00 & 4500 & 0.10 & 0.00 & 0.00 & 0.55 \\ 22 & 16000 & 0.00 & 0.00 & 5300 & 0.10 & 0.00 & 0.00 & 0.21 \\ 23 & 21000 & 0.00 & 0.00 & 3400 & 0.10 & 0.00 & 0.00 & 0.37 \\ 24 & 24000 & 0.00 & 0.00 & 320 & 0.10 & 0.00 & 0.00 & 0.09 \\ 25 & 17000 & 0.00 & 0.00 & 35000 & & 0.10 & 0.00 & 0.00 & 0.92 \\ & & & & & \text { Total: } 0.09 & 0.00 & 0.00 & 0.56 & \end{array}$

\section{Conclusion}

The concern of economic and production managers today is optimal use of resources and saving energy. Since the reduction of energy consumption affects desirable and undesirable output, the present paper has been proposed a new approach for saving energy so the desirable outputs have little affect and undesirable outputs such as non-performing loans are significantly reduced in a way that achieve the minimum reduction of desirable outputs while unchanged the performance of each unit after re-allocation. By running the model for 25 branches of Iranian Tejarat bank we get in total with a 10 percent reduction in staff and 23 percent reduction in costs, the deposits will decrease by 0.09 instead non-performing loans can be reduced by up to 56 percent through strong guarantees while unchanged the performance of unit. Advantages of the proposed model compared to Li et al. [19]'s model are: (1) with inappropriate choice for specific condition that the manager puts, the proposed model (5) is always possible. (2) This model recommend DM to save inputs and reduce undesirable outputs while performance still remains unchanged. In line with this article, it can be suggested that future research can explore saving inputs and reducing undesirable outputs in order to improve efficiency.

\section{References}

[1] Akbari, S., Heydari, J., Keramati, M., Keramati, A. (2019), Designing a Mixed System of Network DEA for Evaluating the Efficiency of Branches of Commercial Bank in Iran. Advances in mathematical finance \& applications, 4(1), 1-13. http://doi.org/10.22034/AMFA.2019.582260.1165.

[2] Amirteimoori, A., \& Emrouznejad, A. (2011), Input/output deterioration in production processes. Expert Systems with Applications, 38(5), 5822-5825. https://doi.org/10.1016/j.cie.2006.10.003.

[3] Amirteimoori, A., \& Kordrostami, S. (2012), Production planning in data envelopment analysis. International Journal of Production Economics, 140(1), 212-218. https://doi.org/10.1016/j.ijpe.2011.09.025.

[4] Amirteimoori, A., \& Shafiei, M. (2006), Characterizing an equitable omission of shared resources: A DEA-based approach. Applied Mathematics and Computation, 177(1), 18-23. https://doi.org/10.1016/j.amc.2005.10.031

[5] Asmild, M., Paradi, J. C., \& Pastor, J. T. (2009), Centralized resource allocation BCC models. Omega, 37(1), 40-49. https://doi.org/10.1016/j.omega.2006.07.006

[6] Athanassopoulos, A. D. (1998) Decision support for target-based resource allocation of public service in multiunit and multilevel systems. Management Science, 44(2), 173187. https://doi.org/10.1287/mnsc.44.2.173 
[7] Bal, H. , Örkcü, H.H., Celebioglu,S. (2010), Improving the discrimination power and weights dispersion in the data envelopment analysis. Computers and Operations Research, 37, 99-107. https://doi.org/10.1016/j.cor.2009.03.028

[8] Bal, H., and Örkcü,H.H. (2007), A Goal programming approach to weight dispersion in data envelopment analvsis. Gazi Universitv Journal of Science, 20, 117-125. https://dergipark.org.tr/en/pub/gujs/issue/7399/96859

[9] C.I. Chiang, M.J. Hwang, Y.H.Liu. (2011), Determining a common set of weights in DEA problem using a separation vector. Mathematical and computer modeling, 54, 2464-2470. https://doi.org/10.1016/j.mcm.2011.06.002

[10] Charnes, A., Cooper, W.W., Rhodes, E. (1978), Measuring the efficiency of decision making units, European Journal of Operational Research, 2 (6), 429-444. https://doi.org/10.1016/0377-2217(78)90138-8

[11] Dietrich Earnhart, (2004), Regulatory factors shaping environmental performance at publicly-owned treatment plants, Journal of Environmental Economics and Management, 48, 655-681. https://doi.org/10.1016/j.jeem.2003.10.004

[12] Du, J., Liang, L., Chen, Y., Bi, G. (2010), DEA-based production planning. Omega, 38, 105-112. https://doi.org/10.1016/j.omega.2009.07.001

[13] Fang, L. (2013), A generalized DEA model for centralized resource allocation. European Journal of Operational Research, 228(2), 405-412. https://doi.org/10.1016/j.ejor.2013.01.049

[14] Fang, Lei, Zhang, C.-Q. (2008), Resource allocation based on the DEA model. Journal of the Operational Research Society, 59 (8), 1136-1141. https://doi.org/10.1057/palgrave.jors.2602435

Golany, B. (1988), An interactive MOLP procedure for the extension of DEA to effectiveness analysis. Journal of the Operational Research Society, 725-734. https://doi.org/10.1057/jors.1988.127

[15] Golany, B., \& Tamir, E. (1995), Evaluating efficiency-effectiveness-equality tradeoffs: A data envelopment analysis approach. Management Science, 41(7), 11721184. https://doi.org/10.1287/mnsc.41.7.1172

[16] Hatami-Marbini, A., Tavana, M., Agrell, P. J., Lotfi, F. H., \& Beigi, Z. G. A. (2015), common-weights DEA model for centralized resource reduction and target setting. Computers \& Industrial Engineering 79, 195-203. https://doi.org/10.1016/j.cie.2014.10.024

[17] Hawdon, D. (2003), Efficiency, performance and regulation of the international gas industry - a bootstrap DEA approach, Energy Policy, 31, 1167-1178. https://doi.org/10.1016/S0301-4215(02)00218-5

[18] Hong, Li.,Wei Yang, Zhixiang Zhou, Chengming Huang. (2013), Resource allocation model's construction for the reduction of undesirable outputs based on DEA methods, 58, 913-926. https://doi.org/10.1016/j.mcm.2012.10.026

[19] Hosseinzadeh Lotfi, F., Hatami-Marbini, A., Agrell, P.J., N. Aghayi and Gholami, K. (2013), Allocating fixed resources and setting targets using a common-weights DEA approach. Computers \& Industrial Engineering, 64(2), 631-640. https://doi.org/10.1016/j.cie.2012.12.006 
[20] Hosseinzadeh Lotfi, F., Jahanshaloo, G.R., Ebrahimnejad, A., Soltanifar, M., and Manosourzadeh, S.M. (2010), Target setting in the general combined-oriented CCR model using an interactive MOLP method. Journal of Computational and Applied Mathematics, 234, 1-9. https://doi.org/10.1016/j.cam.2009.11.045

[21] Hosseinzadeh Lotfi, F., Nematollahi, N., Behzadi, M.H., Mirbolouki, M. (2012), Centralized resource allocation with stochastic data. Journal of Computational and Applied Mathematics, 236(7), 1783-1788. https://doi.org/10.1016/j.cam.2011.10.009

[22] Hosseinzadeh Lotfi, F., Noora. , A.A., Jahanshahloo G.R., Geramia, J, Mozaffari, M.R. (2010), Centralized resource allocation for enhanced Russell models. Journal of Computational and Applied Matematics, 235 (1), 1-10. http://doi.org/10.1016/j.com.2010.05.029

[23] Jahanshahloo, G.R., (2005), Hosseinzadeh Lotfi, F., and Moradi,M. A DEA approach for fair allocation of common revenue. Applied Mathematics and Computation, 160, 719-724. https://doi.org/10.1016/j.amc.2003.11.027

[24] Jean-Francois Henri, Marc Journeault, (2008), Environmental performance indicators: an empirical study of Canadian manufacturing firms. Journal of Environmental Management, 87, 165-176. https://doi.org/10.1016/j.jenvman.2007.01.009

[25] Kordrostami, S., Amirteimoori, A., Jahani Sayyad Novin, M. (2016), Ranking of Bank Branches with Undesirable and Fuzzy Data. Iranian Journal OF Optimization, 8, 71-77. www.ijo.iaurasht.ac.ir

[26] Korhonen, P., \& Syrjänen, M. (2004), Resource allocation based on efficiency analysis. Management Science, 50(8), 1134-1144. https://doi.org/10.1287/mnsc.1040.0244

[27] Lozano, S. and Villa, G. (2004), Centralized resource allocation using data envelonment analvsis. Journal of Productivitv Analvsis. 22(1-2), 143-161. https://doi.org/10.1023/B:PROD.0000034748.22820.33

[28] Lozano, S., Villa, G., \& Canca, D. (2011), Application of centralized DEA approach to capital budgeting in Spanish ports. Computers \& Industrial Engineering, 60, 455-465. https://doi.org/10.1016/j.cie.2010.07.029

[29] Mangena, S.J., Brent, A.C. (2006), Application of a life cycle impact assessment framework to evaluate and compare environmental performances with economic values of supplied coal products, Journal of Cleaner Production, 14, 1071-1084. https://doi.org/10.1016/j.jclepro.2004.04.012

[30] Momeni, Ehsan, Hosseinzadeh Lotfi, Farhad, Farzipoor Saen, R. (2019), Centralized DEA-based reallocation of emission permits under cap and trade regulation. Journal of Cleaner Production, 234, 306-317. https://doi.org/10.1016/j.jclepro.2019.06.194

[31] Seiford, L.M., Zhu, J. (2002), Modeling undesirable factors in efficiency evaluation, European Journal of Operational Research, 142, 16-20. https:// https://doi.org/10.1016/S0377-2217(01)00293-4

[32] Sung-ko Li, Yuk-Shing Cheng. (2007), Solving the puzzle of structural efficiency. European Journal of Operational Research, 2007, 180, 713-722. https://doi.org/10.1016/j.ejor.2006.05.010

[33] Wu, J., An, Q., Ali, S., \& Liang, L. (2013), DEA based resource allocation considering environmental factors. Mathematical and Computer Modelling, 58(5), 1128-1137. https://doi.org/10.1016/j.mcm.2011.11.030 
[34] Wu, J., Zhu, Q., \& Liang, L. (2016), CO2 emissions and energy intensity reduction allocation over provincial industrial sectors in China. Applied Energy, http://dx. doi.org/10.1016/j.apenergy.2016.01.008.

[35] Yang,J.B., Wong, B.Y.H., Xu, D.L., and Stewart T.J. (2009), Integrating DEAoriented performance assessment and target setting using interactive MOLP methods. European Journal of Operational Research, 195, 205-222. https://doi.org/10.1016/j.ejor.2008.01.013

[36] Zhou Jingkun, Zhang Qiaomei. (2011), Research on the environmental protection performance management system structure of party \& government leaders at the county and city levels based on the planning of Poyang Lake ecological economy zone, Procedia Environmental Sciences, 10, 2659-2664. https://doi.org/10.1016/j.proenv.2011.09.413

[37] Zhu, Q., Wu, J., Li, X. and xiong, B. (2017), China's regional natural resource allocation and utilization: a DEA-based approach in a big data environment. Journal of cleaner production, 142(2), 809-818. https://doi.org/10.1016/j.jclepro.2016.02.100 